\title{
Doubting Descartes: How Berkeley's Immaterialism Outshines the Cartesian System
}

\author{
Rocco A. Astore \\ New School for Social Research. Email: Astor421@newschool.edu
}

Received February 23, 2018; Revised March 14, 2018; Accepted March 25, 2018; Published May o7, 2018.

\begin{abstract}
:
The $17^{\text {th }}$-century Rationalist philosopher, Descartes, famously uttered "cogito ergo sum," or "I think; therefore, I am." (1980, 61). Although this declaration caused an irreversible shift in philosophical thought, does it genuinely capture the bond between the nature of existence and consciousness? This essay will commence with an overview of Descartes's method of doubt, and why it led him to conclude that correct reasoning necessarily leads to certain knowledge of self and an awareness of one's uniqueness as a substance (1980, 62-64). Next, by entering the skeptical approach of Immaterialist philosopher George Berkeley, this piece will attempt to cast uncertainty on this foundational Cartesian claim. Lastly, this paper will assert why it is that Berkeley's "esse est percipi," or "to be is to be perceived," portrays the link between existence and thought more precisely than what may be Descartes's most profound articulation.
\end{abstract}

Keywords: Descartes, cogito ergo sum, consciousness, Berkeley, esse est percipi, existence.

\section{Descartes's Doubt}

In the same vein as the Socratic belief that the wise are those who are aware that they know nothing, comes René Descartes's method of doubt (1980, 14-16). To Descartes, the quest for truth commences when one begins to test how well his/her beliefs correspond to the standards of indubitability (1985, 14-16). By this, one may understand Descartes as adhering to the view that beliefs are evident truths if and only if they contain no contradictions (1985, 21-23). Accordingly, to decide if a belief can be nothing other than accurate, one must employ his/her mental faculties, as well as his/her senses, to affirm or deny it as indubitable or contingent (Descartes, 1985, 21-23).

To evaluate the surety or non-contradictoriness of a belief, one must try to address it from an opposing angle, and if he/she cannot conceive or perceive it as other than what it is, then it is undoubtedly indubitable, and thus, true (Descartes, 1985, 25-28). Central to this process of analysis is doubt, for it is this disposition or attitude which serves as reason's means to validate or have good reason to banish ideas if they prove to lack certainty (Descartes, 1985, 46, 53 \& Sorell, 2000, 61-64).

When doubt succeeds in showing that there is a genuine reason to regard a belief as possible, but not necessary, Descartes would claim that it is incorrect to believe that that opinion can be a sturdy foundation for knowledge (1985, 46, 53, Sorell, 2000, 61-64, \& Russell, 1972, 557569). Instead, it is when doubt fails to have power over reason that one may justifiably assert his/her belief as being secure (Descartes, 1985, 37-39). In other words, when challenges brought against an intellectual inclination fail to demonstrate falsity or any inconsistencies of that rational

(c) AesthetixMS 2018. This Open Access article is published under a Creative Commons Attribution Non-Commercial 4.0 International License (http://creativecommons.org/licenses/by-nc/4.o/), which permits non-commercial re-use, distribution, and reproduction in any medium, provided the original work is properly cited. For citation use the DOI. For commercial re-use, please contact editor@rupkatha.com. 
bent, it is the best to erect knowledge on its grounds (Descartes, 1985, 9-13). However, one should keep in mind that from Descartes's standpoint, it is only through doubt that achieving certain knowledge is possible (Sorell, 2000, 61-64). That is because if one were never to disentangle his/her notions, there would never arise new knowledge, and any rectification of beliefs would be unable to come to light (Sorell, 2000, 61-64).

Moreover, the Cartesian method of doubt makes its most memorable appearance in Descartes's Meditations on First Philosophy. In this text, Descartes guides his readers through his journey from radical uncertainty to the absolute surety of self $\left(1980,45^{-51}\right)$. To achieve this clarity of his existence, Descartes begins by imagining a malevolent God, or a demonic entity, with insurmountable power, causing all ideas he held to be, in fact, illusory, and thus, false (1980, 6o$61)$.

Though the possibility of life as guided by a deceptive omnipotent being is alarming, the true purpose of Descartes's example is to show how questioning plays an integral part in the search for truth (1980, 60-61). First, Descartes draws his readers' attention to why " $2+3=5$ " must be true, even if a nefarious force is dishonestly manipulating his mind into believing this equation to be contingent and thus, absent of genuine universality $(1980,59)$.

One reason why Descartes asserts that mathematical truths are examples of indubitability is that even if he is dreaming he can be sure that " $2+3=5$," showing that in either waking life or the imaginary landscapes embarked upon during sleep, there still exists constancies in Nature (1980, 59, 6o-61). Thus, Descartes continues to assert that there must be some role behind his doubt of mathematical surety that ensures, like " $2+3=5$," his existence as a self-sufficient entity. This role, or that of a doubter, Descartes uses as a basis to utter his esteemed "cogito ergo sum," or "I think; therefore, I am." (1980, 59, 6o-61). Accordingly, Descartes moves past his idea of a deceiving deity, for he acknowledges that his mental capabilities must derive from something more perfect than himself since he believes that as a thinking thing it only fits that a mind of greater perfection crafted his own $(1980,53,59,60-61, \& 63-64)$.

Another example Descartes uses to show how doubt could lead to certainty is his analysis of a burning candle. Now, Descartes begins his thought experiment by analyzing how wax starts as a solid and then gradually changes shape as it liquifies (1980,65-67). He then goes on to claim that as a thinking thing, who is self-aware, he can be sure that the wax exists ephemerally, whereas his core identity, which he cannot know as other than his own is of greater stability (Descartes, 1980, 65-67).

This Cartesian analysis of melting wax demonstrates to its author, Descartes, not only that the mind is continuous, especially in comparison to the nature of a candle but also that he exists separately or distinct from material objects (1980, 65-67). As such, one may claim that Descartes's scrutiny of wax is another means by which he uses doubt to affirm something unique about himself that he did not wholly understand before (1980, 66-67). Accordingly, readers may understand this instance of Cartesian doubt as a process of discovery through rational inquiry, which would remain unknown if Descartes refused to investigate the nature of reality and the epistemic profits gained from inward reflection (1985, 46, 53, 111-113, Sorell, 2000, 61-64, \& Copleston, 1993, 87-89).

From these Cartesian claims concerning the nature of mathematics, the "cogito," and the distinction between subject and object, one may infer that these findings all rely on Descartes's method of doubt (Copleston, 1993, 87-89, 116-121, \& 149-152). One reason for this is that without Descartes's use of challenges to affirm the surety of universality as in the case of the non- 
contradictoriness of " $2+3=5$," there would be no room in his system for something such as the immortality of the soul (Copleston, 1993, 149-152). That is, if nothing is truly permanent, including the stability of valid mathematical conclusions, then no fixedness in Nature could be sure, including one's identity, leaving little chance for any essence to continue after death (Copleston, 1993, 117-123).

Moreover, without Descartes's doubting gaze, the chances of discovering the "cogito" would be nil, for one could only affirm that he/she is a doubter if he/she engages in doubt (Copleston, 1993, 107-109). As sure, that he alone is the source of his doubts, Descartes continues to realize the impossibility of his mind being void of the power to escape awareness and the intake of reality (Copleston, 1993, 107-109). Accordingly, he concludes that he is sure of the fact that he is a thinking thing (Copleston, 1993, 116-117). Although odd, the finding of the "cogito," or the grounds of Descartes's ontology of humanity begins in hazy and shrouded knowledge, or doubt, but eventually culminates in self-certainty (Copleston, 1993, 116-118). Thus, when compared to the inherent nature of human reason to begin in an infantile state, and improve over time, Descartes himself believes that doubt is natural to a person's development (1985, 16-18). Finally, the buildup to the "cogito," is reflective of what Descartes would call rational doubt, and not skepticism, for he informs his readers that this method aims toward knowledge and not further uncertainties (1985, 117, 120, 122, \& 125-126).

Furthermore, if Descartes did not question the nature of objects outside himself, then there would be a slim chance for the emergence of his finding that matter is separate from mind (1980, 65-67). That is because, as Descartes observes in the ephemeral wax, that all things purely material are subject to the laws of mechanics alone (1980, 65-67). Conversely, something such as the capability of the mind to be aware of itself, as evident in its freedom to inspect matter under a questionable lens, is justification to assert that matter lacks something the mind does not (Descartes, 1980, 65-67). This power, or the ability the mind possesses to know itself as simple and unified, gives credence to the Cartesian belief that the mind, as indivisible, or static, cannot run by laws that everchanging matter seem to follow (Descartes, 1980, 65-67). Thus, if it were not for Descartes's critique of alterations in objects, like melting candles, he would be unable to journey inward $(1980,65-67)$. For there would be nothing for Descartes to compare himself to, so that he may recognize his mind in a clearer manner, or as more distinct from that which is strictly mechanical (1980, 65-67).

\section{A Critique of Cartesian Philosophy through Berkeley}

According to philosopher George Berkeley, what people usually regard as the material world, is, in fact, only a collection of ideas $(1982,35-36)$. That is, to Berkeley, all is immaterial, and though one may find his theory uncanny, it successfully debunks the indubitability Descartes claims his system possesses $(1982,35-36)$. One example by Descartes that Berkeley would employ to deny the Cartesian understanding of the separation between mind and matter would be Descartes's famed analysis of the melting wax.

As discussed above, Descartes uses his examination of a burning candle to acknowledge the distinction between himself and the objective world (1980, 64-67). First, Berkeley would point out that the only way Descartes could notice a candle burning would be if that candle were a perception of his mind and not a material object $(2014,3-6)$. That is because Berkeley maintains that only things of a similar type could interact $(1982,35-36)$. To better illustrate Berkeley's claim, one may borrow a page from Spinoza who envisions it impossible for a body to touch an idea, or a 
mind to communicate its ideas to a body (1996, 1-3). Hence, to resolve the mind-body problem, Berkeley denies physical reality and instead embraces that all of existence is immaterial (1982, 3536).

Now Berkeley would assert that Descartes's noticing of a burning candle does not prove that his mind is separate from the candle; instead, it affirms that no distinction between the two ultimately exists $(2014,3-6)$. One reason why Berkeley would take this stance is that if the candle were of a genuinely independent nature, it would be unable to undergo any noticeable change, and instead would remain fixed in the eyes of Descartes (1982, 26-29). Additionally, Berkeley would assert that Descartes's surety of himself as being essentially unchanging in comparison to the innate qualities of the candle is faulty as well (1982, 26-29). For Berkeley would not support that Descartes's qualities are inherently his own, because, as the supposed elements of the candle, they too are impermanent (Descartes, 1980, 64-67 \& Berkeley, 1982, 26-29).

To Berkeley, any qualities Descartes can assign to himself, to justify his existence, are erroneous (1982, 26-29). For instance, if one shook Descartes's hand, one would be able to assert that it feels coarse, whereas another may claim it is smooth. As understood by Berkeley, if Descartes's hand were indeed a feature of Descartes, it would have to feel the same to all people, always $(1982,28)$. However, because two people can disagree about the touch of Descartes, what is a part of Descartes himself, is interpretable in various ways, negating its stability as a quality (Berkeley, 1982, 28).

Furthermore, since Descartes understands his hand as part of himself as an extended being, and because it lacks the steadiness of something unchanging, Berkeley would proceed to challenge the very idea that Descartes is physical at all (1982, 28-31). That is because Berkeley adheres to the view that if an entity's secondary qualities are debatable, then it indicates that its primary qualities or those elements inferred to support and give rise to secondary qualities must be mutable as well $(1982,28-31)$. Therefore, because Descartes's hand, which is a secondary quality of his magnitude as a thing, does not exist as steady in perception, people may extend this doubt to the space he occupies, for it as well can appear relative (Berkeley, 1982, 28-31). Lastly, the relativity of the primary and secondary characteristics of things is also secure, because it satisfies that only things alike can interact, rendering the idea that one is separate from what he/she perceives to be a farce (Berkeley, 1982, 28-31).

Moreover, Berkeley would challenge Descartes's claim that mathematics provides indubitability as in the case of " $2+3=5$ " $(1980,59-61)$. First, Berkeley, like Descartes, would assert that mathematics is partially the study of abstract entities (1982, 74-77 \& 1980, 59). In other words, mathematical findings are immaterial in Nature, and as such one may claim that " $2+3=5$ " is a representational equation (Berkeley, 2014, 51-55). Consequently, though Descartes would find this formula to be real in a transcendent way, Berkeley would assert that as representational it is manipulatable by the mind which gives credence to the outlook that not even mathematics is certain $(2014,51-55)$. That is because one may look to the fact that " $4+1=5$," just like " $4.5+.5=5$," or "20 $x .25=5$," and as such there are various ways for the mind to play with mathematical inputs to produce solutions that Berkeley would believe frictionally coexists (2014, 51-55). Lastly, this friction between the sturdiness of mathematical outputs, and the relative ways of reaching them, Berkeley would assert, is irresolvable, and hence, immutable identities are debatable as well (Berkeley, 2014, 51-55).

So, one may question how the relativity of an entity's identity can culminate into a Berkeleyan challenge to the Cartesian "cogito"? First, because nothing indeed possesses primary qualities, Berkeley believes entities must be in the eye of an all-powerful spirit who, by having the 
ability to perceive reality continually, does so out of his/her perfect goodness (Berkeley, 1982, 2629, 65-66). As such, all that is, must be ideas in the mind of a perceiver who would not refuse to forever gaze on the universe, since as the Deity, only his/her perfection could satisfy such a task (Berkeley, 1982, 26-29, 65-66).

From this, one may claim that the only authentically active mind in Berkeley's idealist sketch of reality, is God, leaving Descartes's "cogito" to be incorrect because it attributes mental activity to humankind when it is solely of the power of the Deity $(1982,71-87)$. One reason why Berkeley's challenge to Descartes's "cogito" withstands, is that Descartes, like Berkeley, believes that a cause is more significant than its effect, and as such the originating cause of existence, God, must exceed the powers of humanity $(1985,116-131 \& 1982,24,71-87)$.

Accordingly, if Descartes wishes to hold to the view that all substances rely on God, who is chief amongst substances, then he cannot claim that people share in any power of the Divine (1985, 116-131 \& Berkeley, 1982, 71-87). For by depending on the Deity, people are impotent in comparison to his/her almightiness, and to assert that reality is a product of their minds, would lead to an inconsistency stating that a cause is not as powerful as what it produces, while at the same time, mightier (Descartes, 1985, 116-131 \& Berkeley, 1982, 71-87). However, because something cannot simultaneously be and not be, it is illogical for Descartes to conclude that people have active minds which project ideas on their own (1985, 116-131 \& Berkeley, 1982, 71-87).

Moreover, one can also jeopardize the Cartesian “cogito" because in Berkeley's view it would be merely tautological and could not individuate Descartes, or anyone else who ascribes to his view (1980, 61-63 \& Berkeley, 1982, 24, 26-32, \& 71-87). That is because Berkeley would assert that "cogito ergo sum," by equating thought to existence, which his immaterialism helps to debase, would truly mean "I think; therefore, I am thinking." (Descartes, 1980, 61-63 \& 1982, 24, 26-32, \& 71-87). Consequently, this claim does not provide anyone with further knowledge of himself/herself and thus no one on this basis alone could claim that he/she exists as distinct (Descartes, 1980, 61-63 \& Berkeley, 1982, 24, 26-32, \& 71-87). Accordingly, through Berkeley's lens, Descartes would not be successfully capturing the link between thought and being, and instead, he would just be reaffirming Berkeley's claim that all is immaterial (1980, 61-63 \& 1982, 24, 26-32, \& 71-87).

\section{III. “Esse Est Percipi” or “Cogito Ergo Sum”?}

From Berkeley's immaterialist assertion, that all of reality is representational, comes his esteemed "esse est percipi" $(1982,24)$. This mantra, that Berkeley coins, to sum up, the true ontological foundation of reality and all that it houses, declares that if everything remains in the unceasingly watchful mind of a greater consciousness, or spirit, the observable universe will continue to endure (1982, 25, 64-67, \& 71-87). Hence, Berkeley's "to be is to be perceived," implies that since all entities are, in fact, sensory ideas in the mind of God, then the link between thought and existence is truly a bond between the Deity's Intellect and his/her productive power to think up all that exists (1982, 24-26, 71-87).

In other words, Berkeley's maxim, "esse est percipi," is an existential tenet which, after some analysis, maintains that only entities alike can interact, such as the Deity's ideas appearing as what people understand to be the multiarray of aspects featured in everyday life (1982, 24-27). As such, Berkeley maintains that God is necessarily immaterial since the sensible world, as an assembly of ideas, can only find its roots in an overarching ideating mind, and this ultimate conceiver who gives rise to the realm of appearances is the Deity (1982, 24-27). Concludingly, "esse 
est percipi" also opens the field for Berkeley, to resolve the dichotomy between subject and object, which is also a major issue and challenge found in the Cartesian metaphysical schema (1982, 2427).

As understood by Berkeley, the sustenance of existence relies on God, who is the ultimate subjective spirit and clearly put the relation between subject and object, is more accurately a relation between the Deity's mind, conscious ideas, and non-conscious ideas (1982, 24-27). In other words, Berkeley envisions life as the product of a necessarily omnipotent mind, channeling consciousness through ideas that can sense other ideas around them (1982, 24-27, 64-65, \& 71-87). These ideas that can mindfully view reality include people, and what they incorrectly refer to as objects in their surrounding world are, in fact, those unaware ideas that the Deity's Intellect exudes (Berkeley, 1982, 24-27, 64-65, \& 71-87). Hence, God, as a fixed and eternally active mind, who alone maintains all life, surpasses any mental powers people may think they possess, for if they were not in the perception of God, none could remain in Nature, in any way (Berkeley, 1982, 24-27, 64-65, \& 71-87). Finally, in comparison to Descartes's "cogito," "esse est percipi," captures the bond between mind and body, for it avoids problems of ontological incompatibility and maintains, as both Descartes and Berkeley agree, God's perfection, and people's powerlessness in comparison to it $(1985,131-135,1980,61, \& 1982,24,71-87)$.

Furthermore, unlike Descartes's “cogito ergo sum," Berkeley's "esse est percipi” maintains God's uniqueness as a substance for he/she alone is ceaselessly active or unendingly monitoring, or caring for all that is, through never turning his/her gaze away from existence (1980, 61 \& 1982, 24, 71-87). Though desiring to maintain the same ontological distinctness as Berkeley successfully justifies in his understanding of the Deity, Descartes too believes that God is infinite, and thus surpasses everything else in capability, including people (1985, 128-131, 1980, 61, \& 1982, 24, 71-87). However, Descartes by understanding himself as a thinking thing, or a mentally active entity who also exists materially, fails to secure his assertion that God is supreme because he envisions himself as sharing in some of the Divine's power $(1985,17)$. Lastly, upholding a special existential status for God, while simultaneously claiming he partakes in the Deity's activity, Descartes's system proves faultier than Berkeley's strict immaterialist belief that all that is must ultimately be a derivative of God's mind (1985, 17 \& 1982, 71-87).

Another issue that arises from Descartes's "cogito" is the problem of how he, as a thinking being, could leap from knowing himself as immaterial, and therefore unable to directly mingle with the physical, to an extended, corporeal lifeform (1980, 61-64). To Berkeley, this would be absurd, for it is not the case that a body can interact with an idea or an idea with a body (1982, 3536). Evidence for this is the impossibility of one to speak through his/her knee, or for another knee to understand and respond to that person's call. Hence, Berkeley, who explains reality as a system between a permanently glorious and active perceiver, ideas that can sense, and nonconscious ideas, avoid the dichotomy between mind and body that Descartes's philosophical venture never genuinely resolves (Copleston, 1993, 149-152). Finally, Berkeley's "esse est percipi," or "to be is to be perceived," asserts what Descartes's "cogito" seeks, but outshines it since it steers clear of the issues and errs of the Cartesian belief in, "I think; therefore, I am."

\section{Conclusion}

This piece set out to accomplish three main tasks. The first of these efforts was to unpack Descartes's method of doubt concerning his discoveries of clear and distinct truths, to convey to the reader why Descartes concluded "cogito ergo sum," or "I think; therefore, I am." Next, through 
the passive, or sensory idealism of Berkeley, this essay presented critical challenges to Descartes's understanding of his place in connection to the nature of reality, as well as other findings he asserts as indubitably true. Finally, following a brief criticism of Descartes's "cogito," this text hoped to secure Berkeley's "esse est percipi," or "to be is to be perceived," as a better solution to the problem of how the mind connects to existence, than presented by Descartes.

\section{Bibliography}

Berkeley, George. 1982. Winkler, K. ed., A Treatise Concerning the Principles of Human Knowledge. Indianapolis: Hackett Publishing Co.

Berkeley, George. 2014. An Essay Towards a New Theory of Vision. Middletown: Creative Space Independent Publishing.

Copleston, Frederick S.J. 1993. Modern Philosophy: From Descartes to Leibniz (A History of Philosophy, Vol. 4). New York: Doubleday.

Descartes, René. Cottingham, J., Stoothoff, R., \& Murdoch, D., trans. 1985. The Philosophical Writings of Descartes Volume I. Cambridge: Cambridge University Press.

Descartes, René. Cress, D. A. trans. 1980. Discourse on Method and Meditations on First Philosophy. Indianapolis: Hackett Publishing Co.

Russell, Bertrand. 1972. A History of Western Philosophy. New York: Simon \& Schuster Inc.

Sorell, Tom. 200o. Descartes: A Very Short Introduction. Oxford: Oxford University Press.

Spinoza, Benedict De. Edwin Curley ed. 1996. Ethics. Princeton: Penguin Books.

Rocco A. Astore is a graduate student in Philosophy at the New School for Social Research in New York City, New York, USA. He also holds an MA in Liberal Studies from CUNY: College of Staten Island and a BA in Philosophy from CUNY: Hunter College. His research focuses on major problems within the History of Philosophy, particularly the Early-Modern Period 